\title{
Evaluating the Patient-Reported Outcomes Measurement Information System scales in acute intermittent porphyria
}

\author{
Hetanshi Naik, PhD ${ }^{1}{ }^{1}$, Jessica R. Overbey, $\mathrm{MS}^{2}$, Guy H. Montgomery, PhD², Gary Winkel, PhD², \\ Manisha Balwani, MD, MS ${ }^{1}$, Karl E. Anderson, $\mathrm{MD}^{3}$, D. Montgomery Bissell, MD', \\ Herbert L. Bonkovsky, $\mathrm{MD}^{5}$, John D. Phillips, $\mathrm{PhD}^{6}$, Bruce Wang, $\mathrm{MD}^{4}$, Brendan McGuire, $\mathrm{MD}^{7}$, \\ Siobán Keel, $\mathrm{MD}^{8}$, Cynthia Levy, $\mathrm{MD}^{9}$, Angelika Erwin, MD, PhD ${ }^{10}$ and Robert J. Desnick, MD, PhD ${ }^{1}$
}

Purpose: Acute intermittent porphyria (AIP) is a rare inborn error of heme biosynthesis characterized by life-threatening acute attacks. Few studies have assessed quality of life (QoL) in AIP and those that have had small sample sizes and used tools that may not have captured important domains.

Methods: Baseline data from the Porphyrias Consortium's Longitudinal Study were obtained for 259 patients, including detailed disease and medical history data, and the following PatientReported Outcomes Measurement Information System (PROMIS) scales: anxiety, depression, pain interference, fatigue, sleep disturbance, physical function, and satisfaction with social roles. Relationships between PROMIS scores and clinical and biochemical AIP features were explored.

Results: PROMIS scores were significantly worse than the general population across all domains, except depression. Each domain discriminated well between asymptomatic and symptomatic patients with symptomatic patients having worse scores. Many important clinical variables like symptom frequency were significantly associated with domain scores in univariate analyses, showing responsiveness of the scales, specifically pain interference and fatigue. However, most regression models only explained $20 \%$ of the variability observed in domain scores.

Conclusion: Pain interference and fatigue were the most responsive scales in measuring QoL in this AIP cohort. Future studies should assess whether these scales capture longitudinal disease progression and treatment response.

Genetics in Medicine (2020) 22:590-597; https://doi.org/10.1038/s41436019-0683-y

Keywords: acute intermittent porphyria; quality of life; PROMIS; patient-reported outcomes

\section{INTRODUCTION}

Acute intermittent porphyria (AIP), the most common of four acute hepatic porphyrias, is a rare, dominantly inherited, disorder of heme biosynthesis. Clinically, it is characterized by acute neurovisceral symptoms of severe abdominal pain, nausea, vomiting, muscle weakness, and tachycardia that, if untreated, may lead to seizures, hallucinations, and/or paralysis. ${ }^{1-4}$ These symptoms generally develop after puberty. Recent studies have shown that the true heterozygote prevalence is estimated to be about 1 in 1700 in Caucasians ${ }^{5}$ but the estimated penetrance is very low with $80-90 \%$ of variant carriers never experiencing symptoms (latent). ${ }^{3,5-7}$

Acute attacks can be triggered by certain factors that can lead to significant elevations of the neurotoxic porphyrin precursors 5-aminolevulinic acid (ALA) and porphobilinogen (PBG). Known precipitating factors include hormonal changes, excess alcohol consumption, fasting, and medications that induce cytochrome P450 enzymes. ${ }^{3,7,8}$ Stress has been described as a possible precipitating factor although the extent to which stress induces acute attacks has not been determined. $^{8-10}$ The levels of ALA and PBG are significantly elevated during acute attacks and, in some patients, can remain chronically elevated. ${ }^{7,11}$ There is a wide range of disease severity ranging from sporadic attacks throughout patients' lives to recurrent acute attacks (commonly defined as $\geq 4$ (year). A small subset of patients, particularly females, can experience monthly attacks. ${ }^{1,3,7,12}$ As well, patients may develop symptoms such as chronic pain and neuropathy.

The current treatment for acute attacks is intravenous infusions of hemin (Panhematin in the United States; Normosang in other countries and Europe), which is typically administered once a day for four consecutive days. ${ }^{9,10,13-15}$ Some patients with recurrent attacks receive prophylactic

\footnotetext{
${ }^{1}$ Department of Genetics and Genomic Sciences, Icahn School of Medicine at Mount Sinai, New York, NY, USA; ${ }^{2}$ Department of Population Health Science and Policy, Icahn School of Medicine at Mount Sinai, New York, NY, USA; ${ }^{3}$ Department of Preventive Medicine and Community Health, University of Texas Medical Branch, Galveston, TX, USA; ${ }^{4}$ Department of Medicine and Liver Center, University of California, San Francisco, CA, USA; ${ }^{5}$ Department of Medicine (Section on Gastroenterology \& Hepatology), Wake Forest NC Baptist Medical Center, Winston-Salem, NC, USA; ${ }^{6}$ Department of Internal Medicine, University of Utah, Salt Lake City, UT, USA; ${ }^{7}$ Department of Medicine, University of Alabama-Birmingham, Birmingham, AL, USA; ${ }^{8}$ Division of Hematology, University of Washington, Seattle, WA, USA; ${ }^{9}$ Department of Medicine, University of Miami, Miami, FL, USA; ${ }^{10}$ Genomic Medicine Institute, Cleveland Clinic, Cleveland, OH, USA. Correspondence: Hetanshi Naik (hetanshi.naik@mssm.edu)
} 
hemin, ranging from weekly to monthly infusions, to ameliorate symptoms and prevent hospitalization. ${ }^{16,17}$

It is unclear how disease symptoms and severity affect quality of life (QoL) in individuals with AIP. Previous QoL studies in this population have used the Illness Perception Questionnaire, the Hospital Anxiety Depression Scale, and the EuroQoL. These studies have shown that symptomatic AIP patients have significantly decreased QoL, an increased incidence of anxiety, impaired physical functioning, and that disease negatively impacts their employment. ${ }^{18-20}$ However, these studies were limited in that they consisted only of descriptive analyses, all used different tools, combined the different types of acute porphyria, and sample sizes in each study were relatively small (20-90 patients).

Accurate and standardized QoL information could give health-care providers an accurate assessment of the disease's impairment on a patient's QoL so that specific interventions could be recommended and developed to enhance the lives of these patients. As well, the importance of QoL and patientreported outcomes (PROs) has become part of the US Food and Drug Administration (FDA)'s new drug/indication approvals. Thus, it is important that the tools to measure QoL be carefully evaluated for different diseases. QoL assessments used in previous studies may not have captured all the relevant AIP disease-specific domains nor did they discriminate among patients with different disease severities. Therefore, there is a need for a reliable and valid QoL questionnaire that encompasses the range of symptoms and severities experienced by AIP patients.

The Patient-Reported Outcomes Measurement Information System $\left(\mathrm{PROMIS}^{\circledR}\right)$ initiative of the National Institutes of Health (NIH) was developed to advance PROs. ${ }^{21,22}$ PROMIS consists of a network of collaborative researchers who are developing flexible and dynamic PROs applicable to patients with a wide range of chronic diseases for use in research and clinical practice. $^{22-24}$ The PROMIS tools assess many different domains and although many of the scales are considered psychometrically robust and have been validated in the general US population $^{23}$ and for several diseases, ${ }^{25-27}$ they have not been assessed in many rare diseases. In general, given the nature of these diseases, standard statistical analyses for assessing QoL are limited due to small sample sizes. Therefore, the goal of this study was to assess the PROMIS-57 in a relatively large sample of AIP patients to determine its effectiveness as a PRO measure and explore associations with clinical and biochemical features of the disease to determine if PROMIS scales capture relevant QoL issues in AIP.

\section{MATERIALS AND METHODS}

The study (NCT01561157) was performed at nine sites of the Porphyrias Consortium of the Rare Diseases Clinical Research Network and conducted in accordance with the Declaration of Helsinki. The Institutional Review Boards at the Icahn School of Medicine at Mount Sinai, University of Texas Medical Branch, University of California at San Francisco, University of Alabama, Wake Forest University, University of Utah,
University of Washington, University of Miami, and Cleveland Clinic approved the study and informed consent was obtained. Study procedures were described previously. ${ }^{12}$ Briefly, all patients included had a confirmed diagnosis of AIP with significantly elevated urine PBG ( $>8 \mathrm{mg} / 24$ hours or $\mathrm{g}$ creatinine, or $>2 \times$ increase relative to upper limit of normal) and/or a pathogenic $H M B S$ variant and detailed medical histories were taken at baseline. Patients $\geq 18$ years old were given the PROMIS-57 version 1 scale, which includes the following domains: physical function, anxiety, depression, fatigue, sleep disturbance, satisfaction with social roles, and pain interference. Individual PROMIS responses were scored per the established protocol. ${ }^{28}$ Patients with variegate porphyria and hereditary coproporphyria were excluded from this study because their cutaneous symptoms would have additional QoL effects not applicable to AIP patients.

\section{Statistical analyses}

PROMIS domain scores were compared with the general population scores (standardized mean score of 50 in each domain ${ }^{28}$ using one-sample, two-sided $t$ tests and between self-reported asymptomatic (latent) and symptomatic (sporadic, recurrent attacks, or chronic symptoms) AIP patients using two-sample, two-sided $t$ tests or analysis of variance (ANOVA) as appropriate. Higher scores indicate a greater impact on that domain (e.g., higher anxiety scores mean greater anxiety but higher physical function scores mean better physical function). The impact of disease severity on PROMIS scores was explored using univariate and multiple regression analyses. The covariates included baseline clinical and biochemical features of AIP, gender, age at symptom onset, number of hospitalizations for acute attacks, medical histories of anxiety, chronic nausea, neuropathy, symptom frequency (patients were categorized into severity groups based on frequency of acute attacks they have experienced: sporadic attacks, recurrent attacks, or chronic symptoms), menopausal status, previous or current treatment with hemin, and urine PBG levels. Urine PBG levels were transformed into a fold-over-normal variable by dividing the result by the upper reference limit given by the performing laboratory to account for differing reporting units. Univariate analyses were conducted to determine which covariates should be included in the regression models using a threshold $p$ value of $\leq 0.2$. Models were fit for each of the domain scores. Associations between PROMIS scores and genotype were also assessed. Variants were categorized into missense, nonsense, insertions/ deletions (indels), and consensus splice site lesions. Analyses were considered exploratory and conducted at the 0.05 significance level using SAS version 9.4 (SAS, Cary, NC). ${ }^{29}$

\section{RESULTS}

Two hundred fifty-nine adult patients with AIP were included. Demographics and disease characteristics are shown in Table 1 . The majority of patients were female $(82.2 \%)$, white $(89.2 \%)$, and reported experiencing symptoms either currently or in the past (73.9\%). Disease 
Table 1 Characteristics of patient population

\begin{tabular}{|c|c|}
\hline Characteristics & $N(\%)$ \\
\hline \multicolumn{2}{|l|}{ Gender } \\
\hline Female & $213(82.2 \%)$ \\
\hline Male & $46(17.8 \%)$ \\
\hline \multicolumn{2}{|l|}{ Race } \\
\hline White & $231(89.2 \%)$ \\
\hline Asian & $9(3.5 \%)$ \\
\hline Black & $5(1.9 \%)$ \\
\hline Native American & $2(0.8 \%)$ \\
\hline Multiple & $5(1.9 \%)$ \\
\hline Unknown & $7(2.7 \%)$ \\
\hline Age at enrollment & $\begin{array}{l}\text { Mean 42.9, SD } 15.5 \\
\text { (range } 18-78 \text { ) }\end{array}$ \\
\hline \multicolumn{2}{|l|}{ Reported symptoms } \\
\hline Yes & $195(75.3 \%)$ \\
\hline No (latent patients) & $57(22.0 \%)$ \\
\hline Missing & $6(2.3 \%)$ \\
\hline \multicolumn{2}{|l|}{ Symptomatic patients } \\
\hline $\begin{array}{l}\text { Age (years) at onset of symptoms } \\
(N=178)\end{array}$ & $\begin{array}{l}\text { Mean 25.0, SD } 10.8 \\
\text { (range 11-66) }\end{array}$ \\
\hline \multicolumn{2}{|c|}{ Number of lifetime hospitalizations $(N=195)$} \\
\hline 0 & $32(16.4 \%)$ \\
\hline $1-3$ & $67(34.3 \%)$ \\
\hline $4-6$ & $33(16.9 \%)$ \\
\hline 7-9 & $7(3.6 \%)$ \\
\hline$\geq 10$ & $35(17.9 \%)$ \\
\hline Unsure/missing & $21(10.7 \%)$ \\
\hline \multicolumn{2}{|l|}{ Frequency of acute attacks $(N=195)$} \\
\hline Sporadic acute attacks & $62(31.8 \%)$ \\
\hline Recurrent attacks ( $\geq 4 /$ year) & $88(45.1 \%)$ \\
\hline Chronic symptoms & $29(14.9)$ \\
\hline Other & $10(5.1 \%)$ \\
\hline Missing & $6(3.1 \%)$ \\
\hline
\end{tabular}

severity varied; patients reported a wide range of number of lifetime hospitalizations and $45 \%$ of symptomatic patients reported having recurrent attacks, defined as four or more per year.

\section{Distribution of PROMIS responses}

Two hundred thirty-two patients (89.6\%) completed the PROMIS-57 at baseline. The mean PROMIS domain scores are shown in Table 2. With the exception of the depression domain, each domain had $>25 \%$ of patients with clinically significant impairment, defined as a $\geq 1$ standard deviation worse score than that of the general population mean. The pain interference domain had $40 \%$ of patients with impairment. With the exception of the depression domain, AIP patient mean scores across all domains were significantly worse than the general population. Comparisons of scores between symptomatic and asymptomatic patients showed significantly worse scores in each domain for those who reported symptoms (Fig. 1).

\section{Univariate analyses in symptomatic patients}

PROMIS domain scores were compared between several key clinical features of the disease. Females had significantly worse mean scores in the physical function and fatigue domains. It should be noted that the sample size for symptomatic men was small and therefore limiting ( 20) (Supplementary Table 1).

With the exception of pain interference, mean scores of patients with a history of anxiety showed significantly worse scores in each domain compared with those with no history of anxiety. Patients reporting chronic nausea had significantly worse mean scores in each domain except the depression, anxiety, and physical function domains. Patients with a history of chronic neuropathy had significantly worse mean scores in pain interference, physical function, fatigue, and satisfaction with social roles domains (Supplementary Table 1). However, only 13 patients had a medical history of neuropathy. Patients who have received hemin in the past, likely for more severe disease, had significantly worse scores in pain interference, depression, physical function, and satisfaction with social roles domains. Symptomatic preand postmenopausal women had no significant differences in any of the domains.

Patients with greater disease severity as characterized by acute attack frequency (sporadic, recurrent, or chronic symptoms) had significantly worse mean scores in all the domains, except the anxiety domain (Fig. 2). Age at onset only demonstrated a significant association with sleep disturbance, and age at enrollment only demonstrated a significant association with depression. Number of hospitalizations was significantly associated with pain interference, fatigue, and sleep disturbance. PBG level was not significantly associated with any domain (Supplementary Table 1). Only four patients reported a medical diagnosis of depression at baseline and only seven had fatigue specifically noted in their baseline medical history; therefore, these were not considered as potential predictors.

\section{Multivariable models}

Individual models were refined based on the clinical significance of each predictor and $p$ values. The final reduced models are shown in Table 3. All final models accounted for $>15 \%$ of the variability in domain scores with the exception of the depression, anxiety, and sleep disturbance models, which accounted for only $12.8 \%, 3.4 \%$, and $9.8 \%$ respectively.

Significant predictors of pain interference scores were frequency of symptoms (chronic versus sporadic $\beta=7.27$, $p$ value $=0.007$; recurrent versus sporadic $\beta=7.24, p$ value $=$ $0.0003)$, a history of neuropathy $(\beta=6.27, p$ value $=0.05)$, and a history of nausea $(\beta=5.24, p$ value $=0.02)$. This model accounted for $27.4 \%$ of the variability observed in the pain interference scores. These variables, as well as hemin use, were included in the final reduced model, as the $p$ value of hemin from the univariate analyses was 0.02 and this was thought to be clinically important. The reduced model accounted for $22.9 \%$ of the variability observed in these scores. 
Table 2 Patient-Reported Outcomes Measurement Information System (PROMIS) domain scores

\begin{tabular}{|c|c|c|c|c|c|c|c|}
\hline \multirow[t]{3}{*}{ Domains } & \multirow[t]{3}{*}{$N$} & \multicolumn{4}{|l|}{ Score } & \multirow[t]{3}{*}{ Patients with impairment ${ }^{\mathrm{a}} N(\%)$} & \multirow[t]{3}{*}{$P$ value $^{\mathrm{b}}$} \\
\hline & & \multirow[t]{2}{*}{ Mean } & \multirow[t]{2}{*}{ SD } & \multicolumn{2}{|c|}{ Range } & & \\
\hline & & & & Min & Max & & \\
\hline Depression & 231 & 50.9 & 10.3 & 38.2 & 78.1 & $50(21.6)$ & 0.18 \\
\hline Physical function & 232 & 46.4 & 10.5 & 20.3 & 59.2 & $73(31.5)$ & $<0.0001$ \\
\hline Fatigue & 231 & 55.7 & 11.4 & 33.1 & 77.7 & $86(37.2)$ & $<0.0001$ \\
\hline Sleep disturbance & 231 & 53.6 & 10.6 & 30.5 & 77.5 & $65(28.1)$ & $<0.0001$ \\
\hline Satisfaction with social roles & 221 & 47.2 & 12.1 & 26.9 & 66.1 & $64(29.0)$ & 0.0007 \\
\hline
\end{tabular}

Impairment defined as scores $>1$ SD or 10 units from the population mean.

${ }^{\mathrm{b}} P$ values from one-sample $t$ test comparing observed sample mean with the general population mean of 50 .

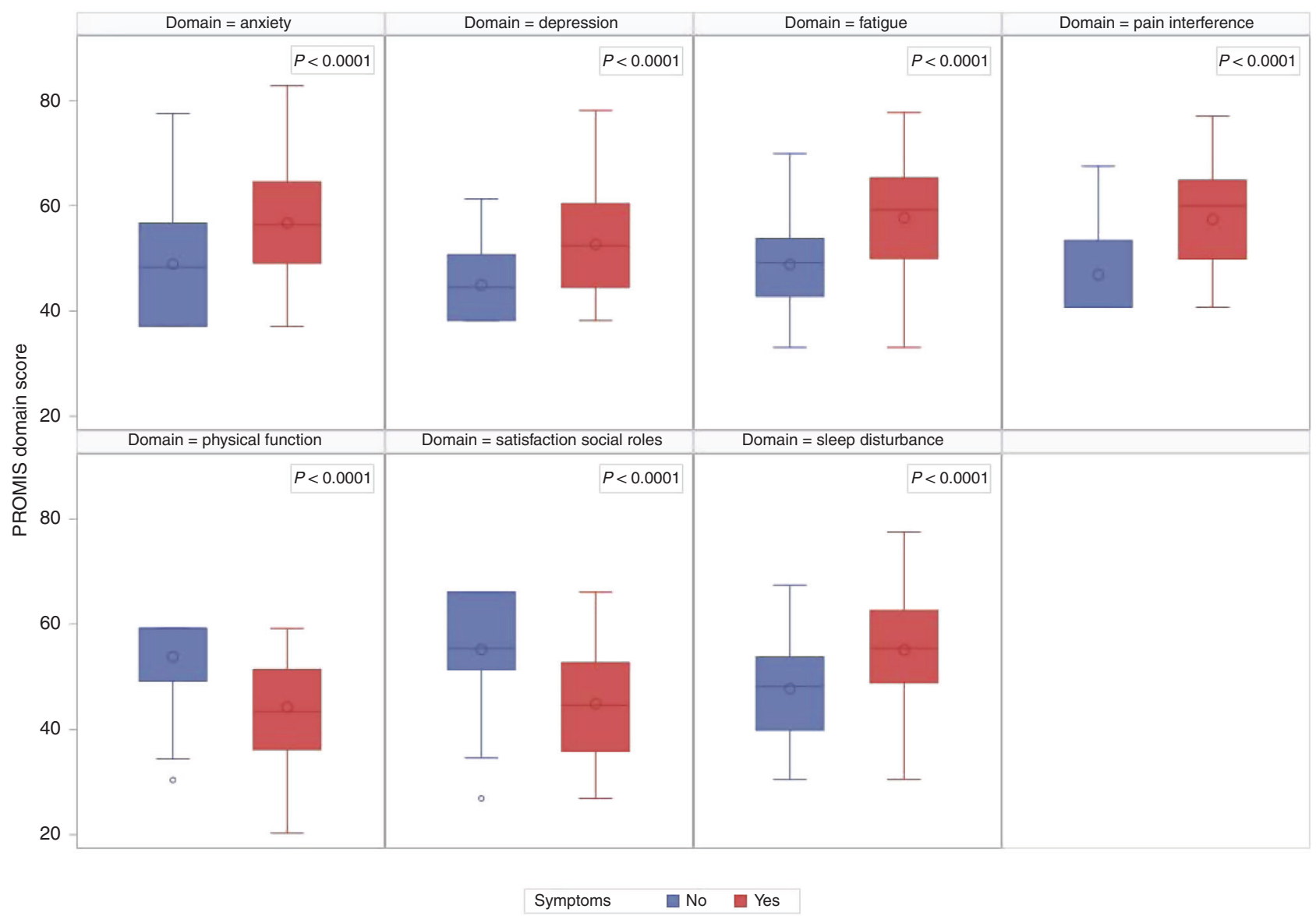

Fig. 1 Box-plots illustrating the discrimination of Patient-Reported Outcomes Measurement Information System (PROMIS) scores between symptomatic and asymptomatic acute intermittent porphyria (AIP) patients. Scores are significantly worse in each domain for symptomatic patients.

The only significant predictors of depression scores were a medical history of anxiety $(\beta=5.36, p$ value $=0.003)$, and frequency of symptoms (chronic versus sporadic $\beta=6.88$, $p$ value $=0.004$; recurrent versus sporadic $\beta=4.71, p$ value $=$ 0.007 ). This model only accounted for $12.8 \%$ of the variability.

Significant predictors of physical function scores were a medical history of anxiety $(\beta=3.97, p$ value $=0.03)$, frequency of symptoms (chronic versus sporadic $\beta=-5.95, p$ value $=$
0.01 ; recurrent versus sporadic $\beta=-4.65, p$ value $=0.007$ ), hemin use $(\beta=-3.78, p$ value $=0.03)$, and a history of neuropathy $(\beta=-9.10, p$ value $=0.001)$. The final reduced model including only these variables accounted for $23.6 \%$ of variability.

Significant predictors of fatigue scores in the final model were only frequency of symptoms (chronic versus sporadic $\beta=9.65, p$ value $=0.0003$; recurrent versus sporadic $\beta=5.66$, 


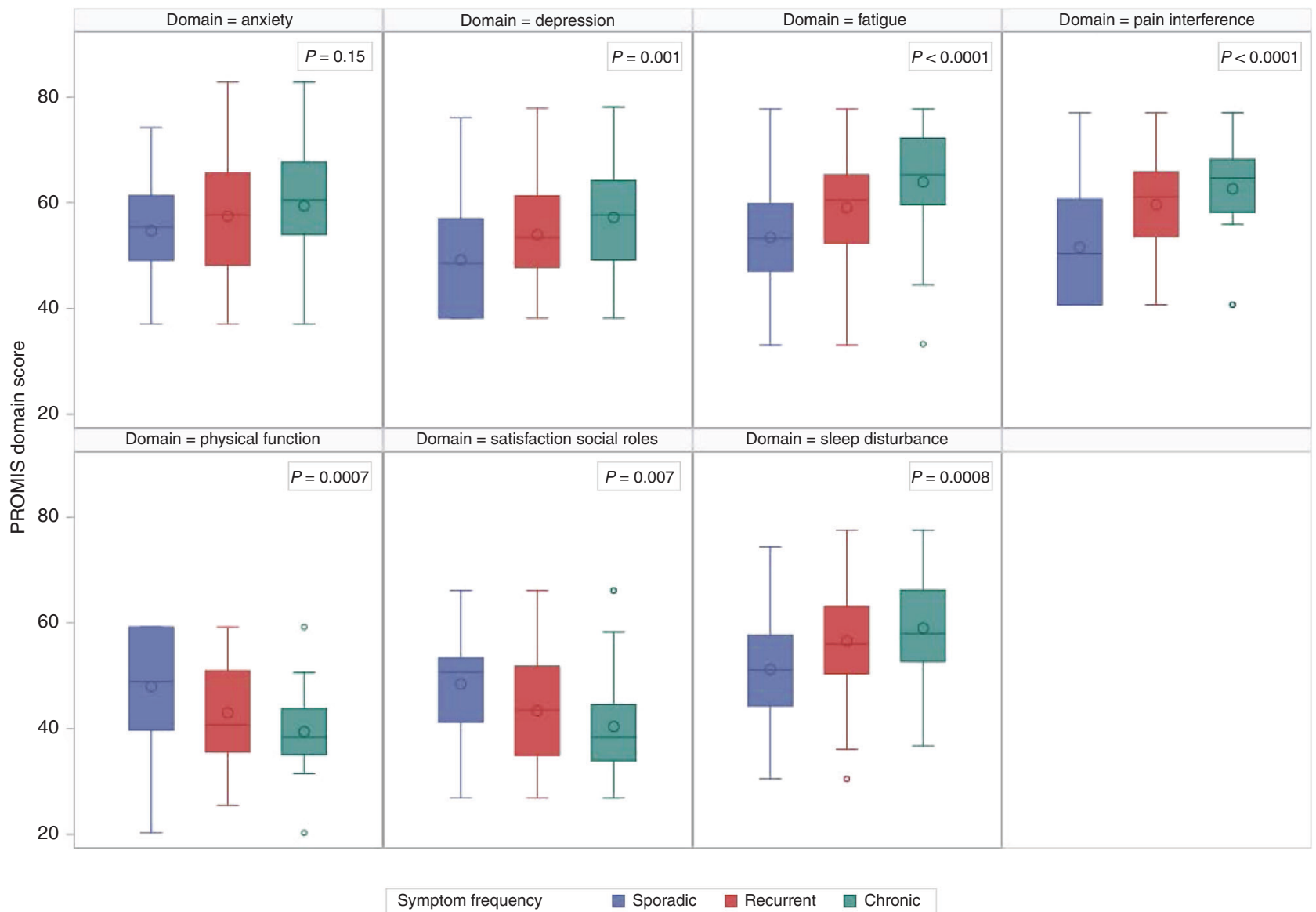

Fig. 2 Box-plots illustrating the differences in Patient-Reported Outcomes Measurement Information System (PROMIS) domain scores for the different severity categories of acute intermittent porphyria (AIP) patients. Scores are significantly worse in each domain for increasingly symptomatic patients, with the exception of anxiety scores.

$p$ value $=0.003)$. The initial model accounted for $20.0 \%$ of the variability observed in these scores. In a reduced model including only frequency of symptoms and a history of neuropathy (which was significant in the initial model), the explained variability dropped to just $12.8 \%$. In the final reduced model, adding back in neuropathy, anxiety, gender, and PBG level increased the explained variability to $16.5 \%$ (Table 3).

There were no significant predictors of anxiety scores. A medical history of anxiety was not included in the initial model because it is redundant. This model only accounted for $3.4 \%$ of the variability in these scores. No reduced model was selected due to this poor model fit.

The only significant predictor of sleep disturbance scores was frequency of symptoms (chronic versus sporadic $\beta=$ $7.18, p$ value $=0.002$; recurrent versus sporadic $\beta=5.35$, $p$ value $=0.002$ ). A history of anxiety was also included in the reduced model because this was felt to be clinically relevant and the $p$ value in the initial model was 0.07 . The reduced model accounts for only $9.8 \%$ of the variability in these scores.

Significant predictors of satisfaction with social roles scores were frequency of symptoms (recurrent versus sporadic $\beta=$ -5.20 , $p$ value $=0.02)$, hemin use $(\beta=-4.84, p$ value $=0.02)$, medical history of anxiety $(\beta=-5.99, p$ value $=0.009)$, and history of neuropathy $(\beta=-7.80, p$ value $=0.05)$. The reduced model accounted for $18.3 \%$ of the variability in satisfaction with social roles scores.

\section{Genotype-PROMIS associations}

Associations between HMBS genotype and PROMIS domain scores were explored. There were no significant differences between patients harboring different variant classes (missense, nonsense, splice site, or insertion/deletion variants) in any of the domains whether symptomatic or asymptomatic.

\section{DISCUSSION}

AIP is a rare genetic disorder of heme biosynthesis with variable clinical severity; few studies have evaluated disease impact on QoL or determined what measurable domains best capture their QoL. A small focus group study, primarily in patients with recurrent attacks, found that patients experience substantial feelings of isolation due to the diagnosis itself as well as its symptoms. ${ }^{30}$ Stress is a possible precipitator of symptoms and many patients struggle with chronic fatigue. ${ }^{30}$ A more recent qualitative interview study found significant disease burden in patients with many reporting chronic symptoms, specifically pain. Of note, this study was conducted in patients with recurrent acute attacks and 
Table 3 Models predicting Patient-Reported Outcomes Measurement Information System (PROMIS) domain scores

$\begin{array}{llll}\text { Variable } & \beta & 95 \% & P \text { value } \\ & \text { estimate } & \text { confidence limits }\end{array}$

\begin{tabular}{|lrrrr}
\hline Pain interference & & & & \\
\hline $\begin{array}{l}\text { Chronic versus sporadic } \\
\text { symptoms }\end{array}$ & 7.27 & 2.07 & 12.46 & 0.007 \\
\hline $\begin{array}{l}\text { Recurrent versus sporadic } \\
\text { symptoms }\end{array}$ & 7.24 & 3.37 & 11.11 & 0.0003 \\
\hline $\begin{array}{l}\text { Panhematin use } \\
\text { Neuropathy }\end{array}$ & 2.95 & -0.77 & 6.68 & 0.12 \\
\hline Nausea & 6.27 & 0.08 & 12.45 & 0.05 \\
\hline $\begin{array}{l}\text { N } 140, R \text {-square }=0.229 \\
\text { Depression }\end{array}$ & 5.24 & 0.98 & 9.50 & 0.02 \\
\hline $\begin{array}{l}\text { Anxiety } \\
\text { Chronic versus sporadic }\end{array}$ & 5.36 & 1.86 & 8.85 & 0.003 \\
\hline $\begin{array}{l}\text { symptoms } \\
\text { Recurrent versus sporadic }\end{array}$ & 4.71 & 1.34 & 8.09 & 0.007 \\
symptoms & & & & \\
\hline
\end{tabular}

$N=164, R$-square $=0.128$

\section{Physical function}

\begin{tabular}{|c|c|c|c|c|}
\hline $\begin{array}{l}\text { Chronic versus sporadic } \\
\text { symptoms }\end{array}$ & -5.95 & -10.52 & -1.37 & 0.01 \\
\hline $\begin{array}{l}\text { Recurrent versus sporadic } \\
\text { symptoms }\end{array}$ & -4.65 & -8.00 & -1.30 & 0.007 \\
\hline Panhematin use & -3.78 & -7.08 & -0.47 & 0.03 \\
\hline Neuropathy & -9.10 & -14.67 & -3.54 & 0.001 \\
\hline Anxiety & -3.97 & -7.50 & -0.43 & 0.03 \\
\hline \multicolumn{5}{|l|}{$N=142, R$-square $=0.236$} \\
\hline \multicolumn{5}{|l|}{ Fatigue } \\
\hline Male & 2.92 & -2.01 & 7.85 & 0.2 \\
\hline Anxiety & 2.10 & -1.76 & 5.96 & 0.3 \\
\hline Neuropathy & 5.47 & -0.73 & 11.68 & 0.08 \\
\hline $\begin{array}{l}\text { Chronic versus sporadic } \\
\text { symptoms }\end{array}$ & 9.65 & 4.55 & 14.74 & 0.0003 \\
\hline $\begin{array}{l}\text { Recurrent versus sporadic } \\
\text { symptoms }\end{array}$ & 5.66 & 1.92 & 9.40 & 0.003 \\
\hline PBG level & 0.02 & -0.01 & 0.05 & 0.2 \\
\hline
\end{tabular}

$N=158, R$-square $=0.165$

\begin{tabular}{|c|c|c|c|c|}
\hline \multicolumn{5}{|l|}{ Anxiety } \\
\hline $\begin{array}{l}\text { Chronic versus sporadic } \\
\text { symptoms }\end{array}$ & 4.34 & -0.81 & 9.49 & 0.1 \\
\hline $\begin{array}{l}\text { Recurrent versus sporadic } \\
\text { symptoms }\end{array}$ & 2.01 & -1.98 & 5.99 & 0.3 \\
\hline Male & 2.23 & -2.94 & 7.41 & 0.4 \\
\hline Age at onset & -0.08 & -0.24 & 0.08 & 0.3 \\
\hline \multicolumn{5}{|l|}{$N=156, R$-square $=0.034$} \\
\hline \multicolumn{5}{|l|}{ Sleep disturbance } \\
\hline Anxiety & 2.71 & -0.78 & 6.19 & 0.1 \\
\hline $\begin{array}{l}\text { Chronic versus sporadic } \\
\text { symptoms }\end{array}$ & 7.18 & 2.59 & 11.78 & 0.002 \\
\hline $\begin{array}{l}\text { Recurrent versus sporadic } \\
\text { symptoms }\end{array}$ & 5.35 & 1.99 & 8.71 & 0.002 \\
\hline
\end{tabular}

$N=164, R$-square $=0.098$
Table 3 continued

\begin{tabular}{lllll}
\hline Variable & $\begin{array}{l}\beta \\
\text { estimate }\end{array}$ & $\begin{array}{l}95 \% \\
\text { confidence limits }\end{array}$ & $P$ value \\
\hline $\begin{array}{l}\text { Satisfaction with social } \\
\text { roles }\end{array}$ & & & & \\
$\begin{array}{l}\text { Chronic versus sporadic } \\
\text { symptoms }\end{array}$ & -5.04 & -10.92 & 0.85 & 0.1 \\
\hline $\begin{array}{l}\text { Recurrent versus sporadic } \\
\text { symptoms }\end{array}$ & -5.20 & -9.40 & -1.00 & 0.02 \\
\hline $\begin{array}{l}\text { Panhematin use } \\
\text { Neuropathy }\end{array}$ & -4.84 & -8.98 & -0.70 & 0.02 \\
\hline $\begin{array}{l}\text { Anxiety } \\
N=136, R \text {-square }=0.183\end{array}$ & -7.80 & -15.58 & -0.02 & 0.05 \\
\hline PBG poph & -10.46 & -1.53 & 0.009 \\
\hline
\end{tabular}

$P B G$ porphobilinogen.

therefore represents the most severe end of the disease spectrum. ${ }^{31}$ Here, we assessed the PROMIS-57 scale in a more diverse, well-characterized group of AIP patients, from asymptomatic to severely affected (Table $\mathbf{1}$ ).

Sample characteristics were similar to those previously described. ${ }^{12}$ All domains had a large proportion of patients with clinically significant impairment lending support to these domains being important in capturing QoL for AIP patients. While depression scores were not significantly different from the general population, it is often observed in patients with severe AIP. Depression is likely still an important domain to measure, especially in patients who develop recurrent attacks, even though it was not observed more frequently than in the general population in our sample.

All the PROMIS domains were able to discriminate well between asymptomatic and symptomatic patients with symptomatic patients having significantly worse scores in every domain. This illustrates that all the PROMIS domains are sensitive to the disease. Many important clinical variables were significantly associated with domain scores in the univariate analyses, showing responsiveness of the PROMIS scales.

Postmenopausal women with AIP are generally thought to be less severely affected than premenopausal women; ${ }^{7,32}$ however, menopause was not a significant variable in any of the PROMIS domains. It is possible that this cohort included more severely affected patients, regardless of menopausal status, or that symptoms of menopause itself obfuscate the results. Alternatively, the sample size of postmenopausal women (40 patients) may have been too small to detect a difference.

In the multiple regression models, the variables that were most frequently significant as predictors of PROMIS domain scores were symptom frequency, hemin use, and medical histories of neuropathy, anxiety, and/or nausea at baseline. Most of the models explained $20 \%$ of the variability observed in the domain scores. The anxiety model did not have any significant predictors. This was surprising, as clinically one would expect patients with more frequent symptoms and indicators of more severe disease (neuropathy, chronic 
nausea, etc.) to be more anxious. Anxiety is commonly seen in AIP patients as previously reported. ${ }^{20}$ In the present study, we observed that anxiety scores were significantly worse than those in the general population and symptomatic patients had significantly worse scores than asymptomatic patients, which is consistent with previous reports. Therefore, it is possible that anxiety is not directly related to disease severity but rather just a general feature of symptomatic patients.

In addition to anxiety, the sleep disturbance model also did not have many clinical features associated with the domain. Disturbances in circadian rhythms of AIP patients has been previously shown ${ }^{33}$ and the recently completed EXPLORE study also showed that many patients with recurrent attacks experience tiredness. Further assessments are needed to determine whether sleep disturbance is a critical domain to be measured when assessing QoL in AIP. It is clear that sleep disturbance is an issue in AIP both clinically and from these data; however, it remains to be elucidated whether it is an issue that stems from other primary domains (pain interference, anxiety, etc.).

The EXPLORE study also showed that the three domains most affected for AHP patients with recurrent attacks were pain and discomfort, anxiety and depression, and ability to perform usual activities as determined by the EQ-5D-5L tool. ${ }^{34}$ However, these findings do not address the issue of which domains are affected primarily and which are secondary to the others.

Overall, both the clinical and biochemical variables were not as useful in predicting the domain scores as it was hoped they would be. While the clinical predictors explained some of the variability observed in PROMIS domain scores, there was much variability left unexplained, and some models were poor. One possibility is that other disease features should be assessed, such as opiate use and/or presence of chronic pain (separate from chronic neuropathy). In addition, the categorization of the data should be reassessed. Some of the predictors may be stronger if broken out individually, for example frequency of hemin use.

While the sample size in this study was limited, this is the largest study of QoL in AIP to date. The main limitations of this study were that the symptoms were all patient-reported and the subjects were predominantly Caucasian and female. Therefore, the results cannot be generalized to other groups, including other ethnicities, and potentially other countries because this population only included US patients. However, most symptomatic AIP patients are female; thus, the demographics of the study population were similar to the AIP patient population as a whole. Given that the symptom categories were patient-reported there may be some miscategorization, specifically between the recurrent and chronic groups. Another limitation may have been that the recall of all the PROMIS domains covered the past seven days with the exception of the physical function domain, which did not specify a time period. It is possible that a longer recall period may be more appropriate in AIP patients. Symptoms can be quite variable especially across the disease severity spectrum and a longer recall period may allow for a more comprehensive picture of how the disease affects patients' QoL. Additionally, urine PBG levels were recorded in varying units and needed to be transformed, which may have affected the results.

\section{Conclusions}

All PROMIS domains (anxiety, depression, pain interference, fatigue, sleep disturbance, physical function, and satisfaction with social roles) were able to discriminate well between symptomatic and asymptomatic patients with AIP. The pain interference, anxiety, and fatigue domains were most associated with the clinical features assessed in symptomatic patients. These domains are consistent with what is observed in clinical practice. The sleep disturbance items should be further assessed to determine if they are relevant to this population as a separate domain. Additional longitudinal modeling to assess whether individual patient variations in PBG/ALA measurements and symptoms over time are associated with PROMIS score changes, as well as assess whether PROMIS can capture changes in QoL due to treatment response, is needed to improve on this QoL study in AIP. Our results demonstrate that the PROMIS domains are sensitive to many of the key clinical variables noted in AIP patients and that these domains are important to accurately measure QoL in this group.

\section{SUPPLEMENTARY INFORMATION}

The online version of this article (https://doi.org/10.1038/s41436019-0683-y) contains supplementary material, which is available to authorized users.

\section{ACKNOWLEDGEMENTS}

This research was supported in part by the Porphyrias Consortium (U54DK083909), which is a part of the National Center for Advancing Translational Sciences (NCATS) Rare Diseases Clinical Research Network (RDCRN). RDCRN is an initiative of the Office of Rare Diseases Research (ORDR), NCATS, funded through a collaboration between NCATS and the National Institute of Diabetes and Digestive and Kidney Diseases (NIDDK).

\section{DISCLOSURE}

H.N. reports consultancies with Alnylam. R.J.D. reports consultancies from Alnylam Pharmaceuticals, Recordati Rare Diseases, and Mitsubishi Tanabe. K.E.A. reports consultancies from Alnylam and grant (clinical trial) support from Alnylam and Mitsubishi Tanabe. D.M.B. reports honoraria from Recordati and grant (clinical trial) support from Alnylam and Mitsubishi Tanabe. H.L.B. reports consultancies form Alnylam, and Recordati Rare diseases and grant (clinical trial) support from Alnylam and Mitsubishi Tanabe. J.D.P. reports consultancies from Alnylam, Recordati, and Agios and grant (clinical trial) support from Mitsubishi Tanabe. S.K. reports grant (clinical trial) support from Alnylam. C.L. reports grant (clinical trial) support from Mitsubishi Tanabe. M.B. reports consultancies Alnylam, Recordati, and Mitsubishi Tanabe, and grant (clinical trial) support from Alnylam and Mitsubishi Tanabe. The other authors declare no conflicts of interest. 
Publisher's note Springer Nature remains neutral with regard to jurisdictional claims in published maps and institutional affiliations.

\section{REFERENCES}

1. von und zu Fraunberg M, Timonen K, Mustajoki P, Kauppinen R. Clinical and biochemical characteristics and genotype-phenotype correlation in Finnish variegate porphyria patients. Eur J Hum Genet. 2002;10:649-657.

2. Meyer UA, Schuurmans MM, Lindberg RL. Acute porphyrias: pathogenesis of neurological manifestations. Semin Liver Dis. 1998:18:43-52.

3. Puy H, Gouya L, Deybach JC. Porphyrias. Lancet. 2010;375:924-937.

4. Tracy JA, Dyck PJ. Porphyria and its neurologic manifestations. Handb Clin Neurol. 2014;120:839-849.

5. Chen B, Solis-Villa C, Hakenberg J, et al. Acute intermittent porphyria: predicted pathogenicity of HMBS variants indicates extremely low penetrance of the autosomal dominant disease. Hum Mutat. 2016;37:1215-1222.

6. Elder G, Harper P, Badminton M, Sandberg S, Deybach JC. The incidence of inherited porphyrias in Europe. J Inherit Metab Dis. 2013;36:849-857.

7. Anderson KE SS, Bishop DF, Desnick RJ. Disorders of heme biosynthesis: X-linked sideroblastic anemia and the porphyrias. In: Scriver CR BA, Sly WS, Valle D, ed. The Metabolic and Molecular Bases of Inherited Disease. Vol 2. 8 ed. New York: McGraw Hill:71.

8. Kauppinen R, Mustajoki P. Prognosis of acute porphyria: occurrence of acute attacks, precipitating factors, and associated diseases. Medicine. 1992;71:1-13.

9. Cappellini MD, Brancaleoni V, Graziadei G, Tavazzi D, Di Pierro E. Porphyrias at a glance: diagnosis and treatment. Intern Emerg Med. 2010:5:S73-80.

10. Stein P, Badminton M, Barth J, Rees D, Stewart MF. Best practice guidelines on clinical management of acute attacks of porphyria and their complications. Ann Clin Biochem. 2013;5:217-223.

11. Bonkovsky HL, Guo JT, Hou W, Li T, Narang T, Thapar M. Porphyrin and heme metabolism and the porphyrias. Compr Physiol. 2013;3:365-401.

12. Bonkovsky HL, Maddukuri VC, Yazici C, et al. Acute porphyrias in the USA: features of 108 subjects from porphyrias consortium. Am J Med. 2014;127:1233-1241.

13. Anderson $\mathrm{KE}$, Bloomer JR, Bonkovsky HL, et al. Recommendations for the diagnosis and treatment of the acute porphyrias. Ann Intern Med. 2005:142:439-450.

14. Bissell DM. Treatment of acute hepatic porphyria with hematin. J Hepatol. 1988;6:1-7.

15. Sassa S. Modern diagnosis and management of the porphyrias. $\mathrm{Br} J$ Haematol. 2006;135:281-292.

16. Bissell DM, Wang B. Acute hepatic porphyria. J Clin Transl Hepatol. 2015;3:17-26.

17. Pischik E, Kauppinen R. An update of clinical management of acute intermittent porphyria. Appl Clin Genet. 2015;8:201-214.

18. Jimenez-Monreal AM, Murcia MA, Gomez-Murcia $V$, et al. Anthropometric and quality-of-life parameters in acute intermittent porphyria patients. Medicine. 2015;94:e1023.
19. Millward LM, Kelly $P$, Deacon A, Senior V , Peters TJ. Self-rated psychosocial consequences and quality of life in the acute porphyrias. J Inherit Metab Dis. 2001;24:733-747.

20. Millward LM, Kelly P, King A, Peters TJ. Anxiety and depression in the acute porphyrias. J Inherit Metab Dis. 2005;28:1099-1107.

21. Carle AC, Cella D, Cai L, et al. Advancing PROMIS's methodology: results of the third Patient-Reported Outcomes Measurement Information System (PROMIS ${ }^{\oplus}$ ) Psychometric Summit. Expert Rev Pharmacoecon Outcomes Res. 2011;11:677-684

22. Cella D, Yount S, Rothrock N, et al. The Patient-Reported Outcomes Measurement Information System (PROMIS): progress of an $\mathrm{NIH}$ Roadmap cooperative group during its first two years. Med Care. 2007:45:S3-S11.

23. Carle AC, Riley W, Hays RD, Cella D. Confirmatory factor analysis of the Patient Reported Outcomes Measurement Information System (PROMIS) adult domain framework using item response theory scores. Med Care. 2015;53:894-900.

24. Reeve BB, Hays RD, Bjorner JB, et al. Psychometric evaluation and calibration of health-related quality of life item banks: plans for the Patient-Reported Outcomes Measurement Information System (PROMIS). Med Care. 2007:45:S22-31.

25. Cook KF, Jensen SE, Schalet BD, et al. PROMIS measures of pain, fatigue, negative affect, physical function, and social function demonstrated clinical validity across a range of chronic conditions. J Clin Epidemiol. 2016;73:89-102.

26. Romero MM, Flood LS, Gasiewicz NK, Rovin R, Conklin S. Validation of the National Institutes of Health Patient-Reported Outcomes Measurement Information System Survey as a quality-of-life instrument for patients with malignant brain tumors and their caregivers. Nurs Clin North Am. 2015;50:679-690.

27. Irwin DE, Atwood CA Jr., Hays RD, et al. Correlation of PROMIS scales and clinical measures among chronic obstructive pulmonary disease patients with and without exacerbations. Qual Life Res. 2015;24:999-1009.

28. Liu H, Cella D, Gershon R, et al. Representativeness of the PatientReported Outcomes Measurement Information System Internet panel. J Clin Epidemiol. 2010;63:1169-1178.

29. SAS 9.4 Help and Documentation [computer program]. Version 9.4. Cary, NC: SAS Institute Inc.; 2013.

30. Naik H, Stoecker M, Sanderson SC, Balwani M, Desnick RJ. Experiences and concerns of patients with recurrent attacks of acute hepatic porphyria: a qualitative study. Mol Genet Metab. 2016;119:278-283.

31. Simon A, Pompilus $F$, Querbes $W$, et al. Patient perspective on acute intermittent porphyria with frequent attacks: a disease with intermittent and chronic manifestations. Patient. 2018;11:527-537.

32. Andersson C, Innala $E$, Backstrom T. Acute intermittent porphyria in women: clinical expression, use and experience of exogenous sex hormones. A population-based study in northern Sweden. J Intern Med. 2003:254:176-183.

33. Larion S, Caballes FR, Hwang $\mathrm{Sl}$, et al. Circadian rhythms in acute intermittent porphyria—a pilot study. Eur J Clin Invest. 2013;43:727-739.

34. Gouya L, Ventura P, Balwani $M$, et al. EXPLORE: a prospective, multinational, natural history study of patients with acute hepatic porphyria with recurrent attacks. Hepatology. 2019 Sep 12; https://doi. org/10.1002/hep.30936 [Epub ahead of print]. 